\title{
Desinformación en las elecciones presidenciales 2018 en Brasil: un análisis de los grupos familiares en WhatsApp
}

\section{Disinformation in the 2018 Brazilian presidential election: An analysis of WhatsApp family groups}

\author{
João Canavilhas; Juliana Colussi; Zita-Bacelar Moura
}

Cómo citar este artículo:

Canavilhas, João; Colussi, Juliana; Moura, Zita-Bacelar (2019). “Desinformación en las elecciones presidenciales 2018 en Brasil: un análisis de los grupos familiares en WhatsApp”. El profesional de la información, v. 28, n. 5, e280503.

https://doi.org/10.3145/epi.2019.sep.03

Artículo recibido el 10-01-2019 Aceptación definitiva: 04-09-2019

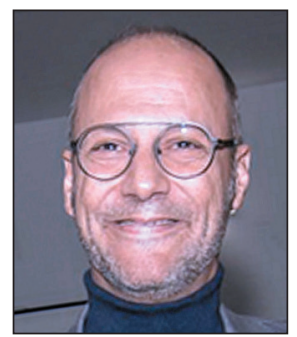

João Canavilhas

https://orcid.org/0000-0002-2394-5264

Universidade da Beira Interior Departamento de Comunicação e Artes

Av. Marquês d'Avila e Bolama.

6200001 Covilhã, Portugal

jc@ubi.pt

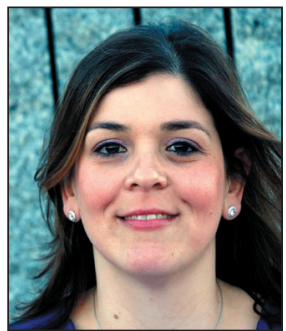

\section{Juliana Colussi $\square$}

https://orcid.org/0000-0002-6324-3857

Universidad del Rosario

Escuela de Ciencias Humanas

Calle 12C № 6-25. Bogotá, Colombia

juliana.colussi@urosario.edu.co

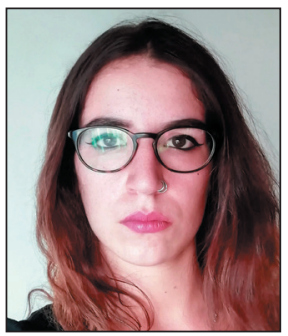

Zita-Bacelar Moura

https://orcid.org/0000-0003-4975-8210

Universidade da Beira Interior

Departamento de Comunicação e Artes

Av. Marquês d'Avila e Bolama.

6200001 Covilhã, Portugal

zita.b.moura@ubi.pt

\section{Resumen}

Esta investigación busca verificar qué tipo de contenidos fue más compartido en los grupos familiares de WhatsApp durante la campaña presidencial brasileña de 2018 y, de éstos, qué porcentaje contenía información falsa. La relevancia del estudio se justifica por la dificultad de acceso a datos de dicha aplicación y porque durante la campaña electoral se comentó en la opinión pública que este canal era una fuente de desinformación. Se ha llevado a cabo el análisis cuantitativo de 472 posts compartidos en diez grupos. El acceso a los datos fue posible gracias a la colaboración de ciudadanos que atendieron nuestra convocatoria para participar en el estudio. Los resultados muestran que la imagen fija con texto fue el tipo de contenido que más circuló en los grupos y que un $60 \%$ de los posts contenía información total o parcialmente falsa. Los hallazgos corroboran la existencia de un círculo de desinformación entre los usuarios de WhatsApp.

\section{Palabras clave}

Desinformación; Noticias falsas; Posverdad; Manipulación; Elecciones; Política; Comunicación política; Redes sociales; Brasil; WhatsApp.

\section{Abstract}

This investigation aims to verify what kind of contents was most shared in WhatsApp family groups during the 2018 Brazilian presidential campaign and which percentage contained false information. The relevance of this study is justified 
because WhatsApp is a closed app and during the campaign was used as a disinformation channel. There was undertaken a quantitative analysis of 472 publications shared in ten groups. The access to this data was possible thanks to the cooperation of citizens who responded to our invitation to participate in the research. The findings show that image with text still corresponds to the most disseminated content in the groups and that $60 \%$ of said publications contained false or partially false information. The discoveries corroborate the existence of a circle of disinformation within WhatsApp users.

\section{Keywords}

Disinformation; Fake news; Post-truth; Manipulation; Elections; Politics; Polítical communication; Social networks; Brazil; WhatsApp.

\section{Introducción}

La elección de Jair Bolsonaro como presidente de la República de Brasil es el más reciente acto electoral en el que las redes sociales online (RSO) han tenido una fuerte influencia. Aunque hay pocos estudios sobre este caso, el hecho de que el candidato no haya realizado ninguna actividad política presencial en la segunda vuelta, junto con la declarada oposición de gran parte de los intelectuales brasileños y de los grupos mediáticos más fuertes, lleva a pensar que las RSO fueron un canal decisivo para su elección. Un rápido análisis a lo que ocurrió en estos espacios durante la campaña, sobre todo en Facebook, Instagram y Twitter, permite verificar que la oposición al actual presidente hizo también una fuerte campaña en las RSO, recurriendo a hashtags de gran éxito como \#EleNão, por lo que WhatsApp podría haber sido un espacio importante porque es una red cerrada y tiene una intensa utilización en Brasil, en particular a nivel de grupos familiares.

Si en las restantes RSO existen APIs que permiten extraer los datos, en el caso de WhatsApp se trata de una tecnología que funciona en circuito cerrado. Esta particularidad justifica la existencia de pocos estudios sobre ella ya que sólo los participantes en los grupos pueden ceder los datos de las conversaciones. Por ser algo inédito, esta investigación buscó justamente estudiar el intercambio de información en estos grupos por ser el ambiente ideal para la diseminación de información falsa, pues al tratarse de grupos familiares había más tolerancia entre los participantes y un menor número de personas para confirmar la información recibida.

Se sabe que la gente tiende a leer sólo los títulos de las noticias (Gabielkov et al., 2016) y que existe un analfabetismo mediático transversal a todas las generaciones (November, 2016), por lo que en estas condiciones se crea el ambiente ideal para que las RSO sean un vivero de información falsa. A diferencia de las demás RSO, donde las propias redes se retroalimentan, en el caso del WhatsApp la información llega siempre de fuera a través de enlaces o contenidos multimedia de éxito en otras RSO, porque son los contenidos con más "me gusta" y con los comentarios más compartidos (Thorson, 2008).

\section{Desinformación: definición y tipos}

Para la editora británica Collins, conocida mundialmente por sus diccionarios, fake news fue la palabra del año en 2017. Esta distinción, motivada por su intensa utilización a lo largo del año, ha merecido una nueva entrada en este diccionario, donde se define como:

"Información falsa, a menudo sensacionalista, difundida bajo el disfraz de noticia"1.

Se trata, evidentemente, de una definición simplificada con un enfoque más lingüístico que enciclopédico, porque en la perspectiva del periodismo el término fake news encierra en sí mismo una contradicción. De los cientos de definiciones de "noticia", recurrimos a Martínez-Albertos (1977) por ser un clásico, pero también porque sintetiza lo esencial para esta discusión:

"Noticia es un hecho verdadero, inédito o actual, de interés general, que se comunica a un público que puede considerarse masivo, una vez ha sido recogido, interpretado y valorado por los sujetos promotores que controlan el medio utilizado para la difusión" (pp. 35-36).

En esta definición, la primera gran característica de la noticia es la veracidad, por lo que la contradicción está en que si es fake no puede ser news. Aunque la palabra pueda facilitar la comunicación con la audiencia, en términos científicos no es satisfactoria. Por ello, la academia ha buscado denominaciones alternativas para clasificar información falsa, desviando su enfoque único en el producto informativo para complementarlo con el grado de intención de desinformar (Tandoc Jr.; Lim; Ling, 2017), por lo cual pasa a ser más utilizada la palabra "desinformación” (Bârgăoanu; Radu, 2018).

El concepto de desinformación, tal y como lo conocemos en la actualidad, no es igual a lo que era en sus inicios. Volkoff (2000) explica que la palabra surge en ruso (dezinformatisya) al final de la II Guerra Mundial, y tiene una naturaleza crítica en cuanto a las prácticas capitalistas que anhelaban "la sujeción de las masas populares" (p. 23). El autor se refiere a un episodio con Pierre Debray-Ritzen y Jean Ferré, en 1982, cuando los tres logran concebir una posible definición para el concepto:

"Técnica que permite proporcionar a terceros informaciones generales engañosas que llevan a organizar acciones colectivas o a difundir los juicios deseados por los desinformadores" (p. 23). 
Según Volkoff, la desinformación actúa mediante cuatro estrategias, que incluyen (Volkoff, 2000, p. 132):

- ocultación de información;

- información incompleta, tendenciosa o simplemente falsa;

- sobreinformación con la intención de saturar la atención y, consecuentemente, se pierda el sentido de lo que es importante;

- comentarios "orientados".

En este trabajo nos centramos en el segundo grupo, que a su vez se divide en siete tipos de contenidos desinformativos en una escala creciente de intencionalidad para desinformar (Wardle, 2017):

1) Sátira o parodia

2) Conexión falsa

3) Contenido engañoso

4) Contexto falso

5) Contenido impostor

6) Contenido manipulado

7) Contenido fabricado

Se abandona así el concepto de fake news para centrar la investigación en la desinformación.

Para Wardle, la "sátira o parodia" es el grado más bajo de desinformación. Tiene potencial para engañar y pretende crear una situación humorística que se convierte en un vehículo de propagación de ideas, pero en general no suele ser su objetivo principal.

El segundo grado de desinformación, "conexión falsa", se refiere a los casos en los que el título no tiene relación con el contenido. Se trata de un intento de atraer la atención del consumidor hacia un determinado contenido usando como cebo un título apetecible, pero sin ningún vínculo con el contenido de la noticia. El mejor ejemplo de este tipo de desinformación es el clickbait (Wardle; Derakhshan, 2018), que se usa intensivamente en las publicaciones online. Es importante no confundir este nivel de desinformación con las técnicas de optimización que incluyen en los títulos algunas palabras muy buscadas por los internautas. En estos casos no se rompe la conexión título-contenido, sólo se optimiza el título o texto, con lo cual no se trata de un proceso de desinformación, aunque en determinados casos funcione como tal.

El siguiente nivel, el "contenido engañoso", trata sobre un tema o una persona recurriendo a información falsa, sea por fotos manipuladas o citaciones falsas. Es una categoría cercana al nivel siguiente, el "contexto falso", en el que se contextualiza un contenido verdadero con información falsa. Lo que tienen en común estos dos niveles es que existe un elemento verdadero para dar alguna confianza al lector, introduciendo contextos falsos que alteran la percepción de la realidad y favorecen la posición del autor.

El "contenido impostor" se produce cuando la información falsa se asigna a fuentes confiables, como periodistas u organizaciones reconocidas. Una vez más se busca entrar en la esfera de confianza del lector a través de la estratagema anterior: tener un elemento verdadero, en este caso las fuentes, pero adulterando la información.

Hasta este punto hablamos de contenidos cuya manipulación es de baja complejidad y puede ser ejecutada por cualquier ciudadano. A partir de este nivel entra la maquinación elaborada para la que son necesarios más conocimientos y recursos técnicos:

"Contenido manipulado" es el proceso de falsificación de información o imágenes preexistentes. Es algo que ha ocurrido a lo largo de toda la historia, siendo muy utilizado en escenarios de conflictos armados o geopolíticos. Para Breton (2001), la manipulación reduce de forma imperceptible la libertad de pensamiento para que las personas no discutan o resistan, aceptando lo que se les propone.

Por último, el "contenido fabricado" es todo lo que es integral y exclusivamente producido para engañar a los receptores. Corresponde al grado más alto de desinformación porque no existe ninguna relación entre los contenidos y la realidad.

Independiente del nivel de desinformación, se sabe que los productores de información falsa buscan que los contenidos manipulados se asemejen a productos periodísticos para entrar más fácilmente en el entorno de proximidad informativa de los lectores. Es cierto que el propio periodismo tiene sus efectos desinformativos como resultado de las rutinas y técnicas (Galdón, 2001), cuando, por ejemplo, la noticia transmite una visión parcial y superficial de la realidad porque el espacio que le está asignado en el periódico o telediario es escaso. Pero este grado de desinformación no tiene la intención de engañar a la audiencia, sólo es reflejo de una limitación en el quehacer periodístico. No es lo mismo que ocurre en las situaciones anteriores, en las que las fuentes de las noticias no son los medios tradicionales, sino organizaciones con objetivos políticos que buscan acercar su mensaje a los formatos del periodismo por ser una actividad con relevancia social reconocida. Es este tipo de información intencionadamente falsa, sobre todo en los últimos niveles -contenido manipulado y contenido fabricado- que analizamos en una de las plataformas más exitosas de la web 2.0: la red social online WhatsApp. 


\section{Web 2.0: burbujas de información y desinformación}

¿Pero que cambió para que un fenómeno que siempre ha existido -la desinformación- haya ganado tamaña dimensión? ¿Cómo lograron estas organizaciones acceder a los ciudadanos sin la intermediación de los medios de comunicación? La gran diferencia es la emergencia de Internet y la popularización de las diversas aplicaciones de la web 2.0, primero la blogosfera y más tarde las redes sociales online. Estas tecnologías desencadenaron procesos informativos descentralizados, en el que los medios tradicionales no tienen ningún control. Con acceso directo al público, los sujetos que buscan difundir un determinado mensaje falso pasan a competir con los medios tradicionales. En este caso, acceden al espacio público que es la Web, lo que posibilita múltiples alternativas para entrar en las burbujas informativas creadas por las RSO, como Facebook, Instagram, Twitter o WhatsApp.

Los estudios sobre las elecciones estadounidenses de 2016, que eligieron a Donald Trump, han buscado identificar alguna relación entre las RSO y los resultados electorales (Alcott; Gentzkow, 2017). El hecho de que el 62\% de los adultos estadounidenses se informara a través de las redes sociales (Gottfried; Shearer, 2016) ha sido fundamental para diseñar la estrategia de las campañas. Además se concluyó que las informaciones falsas con éxito en Facebook (muy compartidas/comentadas) eran más populares que la mayoría de las noticias producidas por los medios mainstream (Silverman; Singer-Vine, 2016). Una conclusión preocupante es que el público declara creer en información falsa en un $75 \%$ de las ocasiones que se ve confrontado con ella (Silverman; Singer-Vine, 2016). Castells (2012) analiza profundamente lo que han logrado ciudadanos y activistas en acciones concertadas contra gobiernos y regímenes autoritarios usando las RSO, desde el Occupy Wall Street a la Primavera Árabe, concluyendo que las RSO son espacios de acción para las campañas políticas.

Las estructuras que detentan el poder político, ejecutivo y financiero de las sociedades saben que su poder está fundado en el monopolio de los canales de comunicación. Es por ello que esos espacios de autonomía de los que habla Castells (2012) son peligrosamente útiles a estas estructuras. Se plantea que

"el paisaje de las comunicaciones se vuelve más denso, más complejo y más participativo", de manera que "la población interconectada está ganando mayor acceso a la información, más oportunidades de integrar el discurso público y una aumentada capacidad de organizar acciones colectivas" (Shirky, 2011, p. 29).

Por otra parte, Fuchs (2013) tiene una visión mucho más tecno-determinista de lo que pueden llegar a ser las RSO en el ejercicio del poder, pues afirma que:

"Ios actores políticos dominan y centralizan la formación del discurso, debate, asamblea y opinión en las redes sociales" (p. 130).

Así, podemos comprender cómo estos dos espacios de discusión pública -los escenarios de las campañas electorales tradicionales y las redes sociales- tienen una tendencia creciente a fusionarse.

\subsection{Microesferas de información}

El concepto de esfera pública (Habermas, 2003) se refiere al espacio de diálogo y actuación política de las personas que constituyen la sociedad. Dentro hay una esfera más pequeña, la esfera política, más hermética que la primera. Es en este ambiente que la sociedad construye su opinión pública, ya que es eminentemente un espacio de discusión y decisión. Aun así, esta esfera pública exige la presencia de intermediarios, como son los medios de comunicación, que establecen el puente entre la esfera pública, la privada y la política.

Al mencionar el concepto de público propuesto por el autor alemán, Medeiros (2013) defiende que Internet contiene un espacio público sin intermediarios o regulaciones institucionales, de manera que "se posibilitan nuevas formas de que los sujetos puedan convivir, pensar y manifestarse" (Medeiros, 2013, pp. 27-28). Es decir, "el sujeto de esa esfera pública es el público en cuanto portador de la opinión pública" (Habermas, 2003, p. 14).

Las redes sociales, en este caso, no son más que una extensión de esta esfera pública. Es en este espacio social reconfigurado con nuevas reglas de interacción y nuevos moldes de socialización donde logran medrar los procesos desinformativos. Las RSO son, en sí mismas, una modalidad de esfera pública que proporciona un espacio de circulación de informaciones y debate y donde se forman las opiniones (Recuero, 2009). La autora concluye que estas burbujas de información son ahora microesferas públicas donde opiniones y ideas circulan de forma libre y sin un control central.

Las redes sociales funcionan con algoritmos que proporcionan a sus usuarios contenidos que son semejantes a los que habitualmente consumen. Cuando la narrativa de los medios tradicionales está de acuerdo con el discurso imperante en el grupo, o un participante distorsiona el contexto de una noticia, las burbujas informativas refuerzan una opinión.

Törnberg (2018) hace notar que los fenómenos de las cámaras de eco y de la difusión de la desinformación están interconectados, ya que los grupos homogéneos de utilizadores con preferencia por auto-confirmación parecen ser capaces de providenciar campos de cultivo donde crecen los rumores y la desinformación. En un espacio digital en el que los ciudadanos promueven sus
Internet y las redes sociales no son más que una extensión de la esfera pública y es en este espacio social reconfigurado con nuevas reglas de interacción y nuevos moldes de socialización donde los procesos desinformativos funcionan 
narrativas favoritas se generan grupos polarizados que se resisten a la información que no va a favor de sus creencias, y esto puede ser lo que hace que Internet sea fértil para el crecimiento de la desinformación. Estas ideas se aproximan a la teoría de la fabricación de consentimiento (Chomsky; Hernan, 1988): las personas, inmersas en el entretenimiento de la interacción con los otros, se creen bien informadas, lo que genera una falsa sensación de conocer la verdad. En este escenario es fácil desinformar, y más aún si tenemos en cuenta lo muy herméticas que son algunas redes, como es WhatsApp.

\section{Método}

El objetivo principal de esta investigación es verificar la presencia de noticias falsas sobre las elecciones presidenciales de octubre de 2018 en Brasil en grupos familiares en WhatsApp. En concreto, se pretende conocer:

1. El tipo de contenido multimedia más compartido sobre temas políticos.

2. Porcentage de posts con desinformación recibidos en cada grupo familiar.

Para responder a nuestro objetivo se realizó un análisis de contenido web (Herring, 2010), que contempla la inclusión de elementos propios de Internet, como son los enlaces y elementos multimedia, de manera que complementa el análisis de contenido tradicional (Bardin, 1977; Krippendorf, 2004). Entre las variables estudiadas se encuentran:

- Formato: contabilizar el número de publicaciones con imagen fija, vídeo, animación, texto, pdf o audio.

- Información: verificar qué porcentaje del contenido compartido en los grupos WhatsApp presenta datos falsos.

Respecto de la muestra, se han seleccionado contenidos multimedia sobre política compartidos en diez grupos de familia en WhatsApp a lo largo del mes de octubre de 2018, en los que participaban 190 personas de varias regiones del país (tabla 1). Con el fin de tener acceso al material de dichos grupos se publicó una convocatoria en diferentes agrupaciones en Facebook y WhatsApp, con el compromiso de que no se publicarían ni se usarían datos personales en el análisis. En total se recibieron las publicaciones de 14 grupos, de los cuales se descartaron cuatro porque los datos estaban incompletos.

Conviene señalar las dificultades en el proceso de recogida de datos, teniendo en cuenta que WhatsApp es una aplicación basada en la arquitectura peer-to-peer. Es decir, para llevar a cabo estudios sobre mensajes compartidos en aplicaciones como ésta los investigadores dependen de la colaboración de usuarios para acceder a los datos. Durante los quince días en que la convocatoria estuvo abierta en redes sociales, 22 personas nos dijeron vía comentarios en Facebook que no podían colaborar con la investigación por dos motivos:

- habían salido del grupo de familia en WhatsApp debido a las discusiones sobre las elecciones, o

- habían borrado el contenido del grupo para desocupar espacio en el smartphone.

Además, nos encontramos con dificultades técnicas en los aparatos con sistema operativo Android, que al exportar el chat permite adjuntar un número limitado de documentos. En este caso, los usuarios nos reenviaron los posts vía chat de WhatsApp. Los usuarios del sistema iOS no tuvieron inconvenientes para exportar los ficheros. En este sentido, a pesar de presentar una muestra relativamente pequeña en familias (10), esta investigación es de gran relevancia por analizar datos de una app cerrada, algo inédito, y tener la participación de 190 personas.

Para seleccionar los grupos familiares de WhatsApp se aplicaron tres criterios:

- que se intercambiaran mensajes sobre las elecciones presidenciales;

- que el grupo estuviera conformado por al menos cuatro personas de una familia; y

- que el usuario que nos enviara el contenido no hubiera borrado mensajes o contenidos compartidos en el grupo durante el mes de octubre de 2018.

Tras recibir y organizar los datos de cada grupo, se seleccionaron los contenidos multimedia -texto, imagen fija, vídeo, enlace, pdf y audio- compartidos que correspondían a temas políticos, obteniendo una muestra con 472 publicaciones. Éstas fueron verificadas para identificar si se trataba de una información: 1) completamente verdadera; 2) parcialmente falsa, o 3) totalmente falsa. Este análisis se basó en un manual del portal de noticias brasileño $G 1^{2} y$, como consecuencia se examinaron los siguientes aspectos de los contenidos:

- Constatar si el título era muy llamativo, la historia era muy inusitada o el tema parecía exagerado.

- Verificar si las informaciones aportadas eran ambiguas. 
- Comprobar la fecha de la publicación, pues había contenidos que volvían a circular.

- Averiguar la veracidad de las imágenes y de los audios.

- Saber si el contenido fue publicado por un medio de comunicación profesional.

- Investigar las fuentes de información.

\section{Resultados y discusión}

El análisis de los datos nos posibilita validar el ciclo de desinformación que se ha dado en los grupos familiares de WhatsApp durante las elecciones presidenciales en Brasil. Los resultados apuntan que un $90 \%$ de los grupos compartió contenidos sobre los candidatos y sus respectivos partidos políticos a lo largo de octubre de 2018. Sólo el grupo 7 se dedicó exclusivamente a temas familiares, sin mencionar asuntos políticos (tabla 2).

La tabla 3 informa que en los 472 posts destacó la circulación de imágenes fijas (48,5\%), que solían venir acompañadas de algún tipo de información textual. Las tres imágenes que componen la figura 1 muestran que este tipo de publicación puede ser, por ejemplo, un meme aparentemente producido por un usuario, un pantallazo de un post en redes sociales o una pieza de propaganda electoral.

El segundo formato más distribuido en los grupos de WhatsApp corresponde a las publicaciones audiovisuales (32,6\%). A continuación se encuentran los enlaces $(8,7 \%)$, la información textual publicada directamente en el chat (7\%), el audio (3\%) y el pdf $(0,2 \%)$.

Respecto a la veracidad de la información de los contenidos políticos compartidos en los grupos familiares, los resultados señalan que un $60 \%$ corresponde a información parcial o completamente falsa (tabla 4). Los posts clasificados como "información falsa" $(38,8 \%)$ superaron la cifra de los que contenían información verdadera (35,4\%). Los contenidos que mezclaban datos verdaderos y falsos representaron un $21,2 \%$ de las comparticiones. Un 4,6\% del material analizado no se encuentra en ninguna de las clasificaciones anteriores, debido a que no se pudo averiguar la veracidad de la nota ni tampoco su procedencia.

Las publicaciones con informaciones totalmente falsas no sólo fueron originadas por ciudadanos, sino que también formaban parte de la estrategia de las campañas electorales. En la figura 2, una serie de imágenes tergiversan las propuestas de gobierno de Jair Bolsonaro y Fernando Haddad, usando información falsa con el fin de obtener un mayor número de votos para el primer candidato. Éste corresponde a los niveles más altos de desinformación a los que se refiere Wardle (2017) como "contenido manipulado" y "contenido fabricado".

Las informaciones falsas distribuidas en los grupos familiares tienen

Tabla 2. Número de posts sobre política por grupo familiar en WhatsApp

\begin{tabular}{|c|c|}
\hline Grupos de familia & No de posts \\
\hline Grupo 1 & 54 \\
\hline Grupo 2 & 14 \\
\hline Grupo 3 & 50 \\
\hline Grupo 4 & 115 \\
\hline Grupo 5 & 41 \\
\hline Grupo 6 & 79 \\
\hline Grupo 7 & 0 \\
\hline Grupo 8 & 40 \\
\hline Grupo 9 & 47 \\
\hline Grupo 10 & 32 \\
\hline Total & 472 \\
\hline
\end{tabular}

Tabla 3. Formatos de los contenidos sobre política compartidos en los grupos de WhatsApp

\begin{tabular}{|l|c|c|}
\hline \multicolumn{1}{|c|}{ Formatos } & Número & \% \\
\hline Imagen fija & 229 & 48,5 \\
\hline Vídeo & 154 & 32,6 \\
\hline Enlace & 41 & 8,7 \\
\hline Texto & 33 & 7,0 \\
\hline Audio & 14 & 3,0 \\
\hline pdf & 1 & 0,2 \\
\hline Total & 472 & 100 \\
\hline
\end{tabular}

Tabla 4. Número de publicaciones falsas compartidas en los grupos de WhatsApp

\begin{tabular}{|l|l|l|}
\hline \multicolumn{1}{|c|}{ Información } & \multicolumn{1}{c|}{ Número } & \multicolumn{1}{c|}{$\%$} \\
\hline Falsa & 183 & 38,8 \\
\hline Verdadera & 167 & 35,4 \\
\hline Parcialmente falsa & 100 & 21,2 \\
\hline Otros & 22 & 4,6 \\
\hline
\end{tabular}
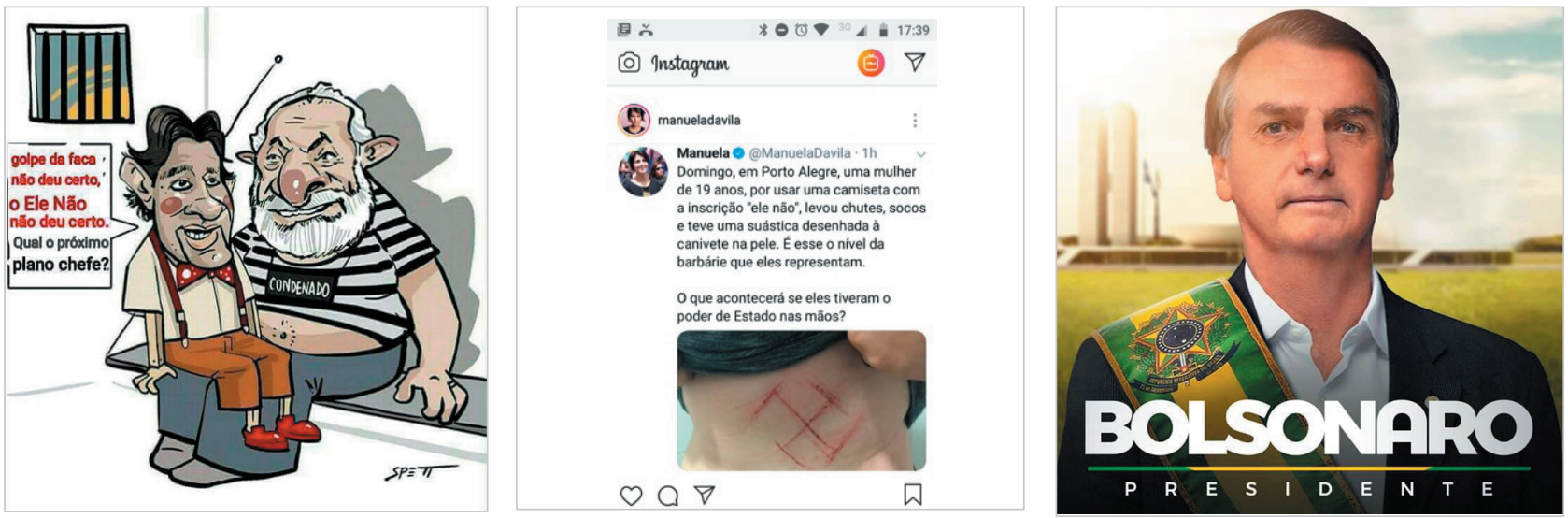

Figura 1. Composición de un meme, un post de Instagram y una pieza de propaganda, que circularon en los grupos 

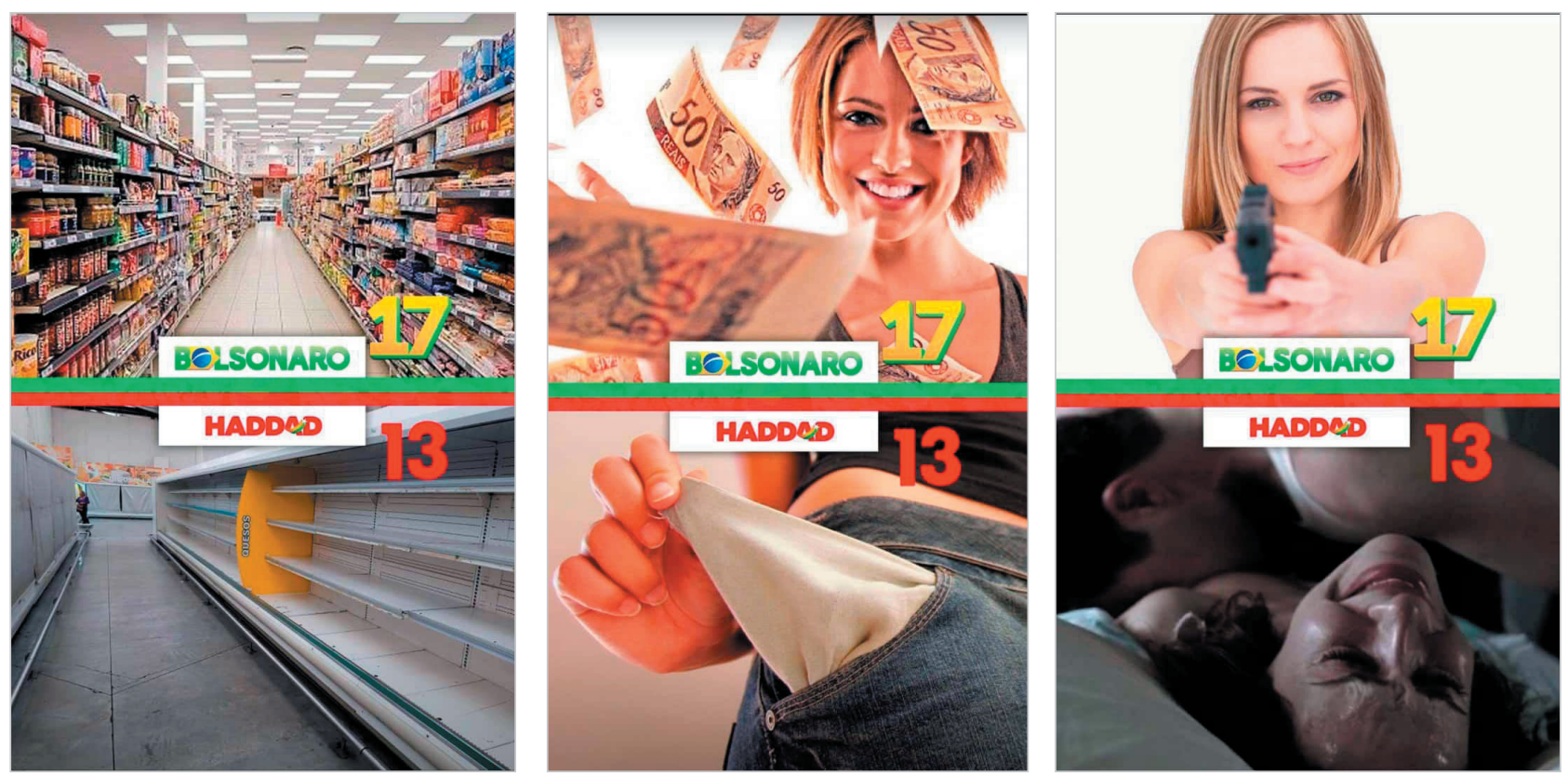

Figura 2. Serie de imágenes de propaganda política de Bolsonaro en las que se usa información falsa

también otros formatos, como los vídeos editados o enlaces. Un ejemplo es el vídeo del ministro suizo Hans-Rudolf Merz, que tuvo un ataque de risa en el Parlamento en septiembre de 2010 mientras leía unas normas comerciales. Antes de circular en WhatsApp la pieza fue editada con subtítulos para simular que el parlamentario estaba riéndose del expresidente brasileño Lula da Silva y exponiendo un discurso contra él y los integrantes de su partido. Entre las noticias falsas se encuentran aún posts de artistas en redes sociales que nunca se publicaron en sus respectivas cuentas, lo que Wardle (2017) tipifica como "contenido impostor".

Los diferentes tipos y la elevada cifra de información falsa sobre las elecciones presidenciales en Brasil diseminadas en los grupos familiares de WhatsApp revelan el nivel de desinformación de los usuarios, que suelen compartir contenidos sin verificarlos. De esta manera se desencadena la viralización de información falsa que, en este caso específicamente, beneficia un candidato en detrimento de otros, además de limitar la libertad de pensamiento de los ciudadanos para debatir sobre asuntos de interés público (Breton, 2001).

Por último, los resultados reflejan que las informaciones verdaderas $(35,4 \%)$ se refieren sobre todo a noticias o artículos de opinión publicados por medios de comunicación profesionales. Se trata de vídeos, enlaces, textos o pantallazos de la publicación en redes sociales de medios de referencia, lo que refuerza la importancia del periodismo profesional para la democracia. No obstante, en este caso, la prensa aparenta haber tenido menos fuerza que los productores de información falsa.

\section{Conclusiones}

Las informaciones falsas son pensadas y publicadas en las RSO para lograr una gran circulación entre los usuarios de dispositivos móviles. Se recurre a distintas aplicaciones digitales con el fin de adulterar fotografías o tweets, editar vídeos y crear nuevas grabaciones en audio sin la inclusión de fuentes informativas verídicas. Estos contenidos distribuidos por WhatsApp también suelen usar personalidades públicas para manipular al público, que está encerrado en sus microesferas donde mantiene un falso sentimiento de conocer la verdad.
Los diferentes tipos y la elevada cifra de información falsa sobre las elecciones presidenciales en Brasil diseminadas en los grupos familiares de WhatsApp revelan el nivel de desinformación de los usuarios

A través de esta investigación se confirma que las informaciones total o parcialmente falsas sobre política son las que tuvieron mayor circulación en los grupos familiares en WhatsApp durante el mes de las elecciones presidenciales en Brasil. Ello corrobora la existencia de un círculo de desinformación entre los usuarios de dicha aplicación-red.

La información total o parcialmente falsa que circuló en estos grupos se caracteriza por usar imágenes fijas con información textual, emplea un lenguaje simple, apropiado para ser compartido en la movilidad, además de utilizar contenidos manipulados y fabricados. También se dieron casos de "contenido impostor" atribuido a determinadas personas. 
Los datos muestran que mientras parte de los posts aparenta ser de autoría de ciudadanos, otras publicaciones demuestran tener calidad profesional, como si hubiesen sido creadas por los responsables de las campañas políticas de cada candidato. En ambos casos aprovechan informaciones falsas y manipulaciones para engañar al elector, lo que conlleva a una limitación de la libertad de expresión y del debate sobre temas de interés social. Se ratifica la hipótesis de que los grupos analizados han funcionado como un canal de circulación masiva de noticias falsas durante el período preelectoral, es decir, han funcionado como un canal de desinformación.

Una limitación de este estudio es la dimensión de la muestra analizada (10 familias), pero hay que destacar el número significativo de participantes (190). A pesar de la limitación se espera que esta investigación sobre los contenidos que circulan por una red social cerrada pueda contribuir a que los participantes en grupos entiendan que los investigadores aseguran su anonimato y, de esa forma, estén dispuestos a participar en nuevas investigaciones sobre estas redes cerradas, que siguen siendo un espacio desconocido. Será interesante contrastar los resultados de la presente investigación con los de futuros estudios y conocer mejor las dinámicas de desinformación en grupos de WhatsApp.

\section{Notas}

1. Búsqueda efectuada en: https://www.collinsdictionary.com

2. El manual, que ayuda al usuario a identificar si un contenido es verdadero o falso, forma parte del proyecto periodístico Fato ou fake (Hecho o falso) de G1:

https://g1.globo.com/retrospectiva/2018/noticia/2018/12/22/fato-ou-fake-mais-de-mil-checagens-no-ano.ghtml

\section{Referencias}

Allcott, Hunt; Gentzkow, Matthew (2017). "Social media and fake news in the 2016 election". Journal of economic perspectives, v. 31, n. 2, pp. 211-236.

https://www.nber.org/papers/w23089

https://doi.org/10.3386/w23089

Bardin, Laurence (1977). Análise de conteúdo. Lisboa: Edições 70. ISBN: 9724408981

Bârgăoanu, Alina; Radu, Loredana (2018). “Fake news or disinformation 2.0? Some insights into Romanians' digital behaviour". Romanian journal of European affairs, v. 18, n. 1, pp. 24-38.

http://rjea.ier.gov.ro/wp-content/uploads/articole/RJEA_vol.18_no.1_June2018_art.2.pdf

Breton, Philippe (2001). A palavra manipulada. Lisboa: Editorial Caminho. ISBN: 9789722121156

Castells, Manuel (2012). Redes de indignación y esperanza: los movimientos sociales en la era de internet. Madrid: Alianza Editorial. ISBN: 9788420609607

Chomsky, Noam; Herman, Edward S. (1988). Manufacturing consent: The political economy of mass media. https://focalizalaatencion.files.wordpress.com/2012/08/herman-chomsky-2002-manufacturingconsent.pdf

Fuchs, Christian (2013). Social media: A critical introduction. London: Sage. ISBN: 9781446257319

Gabielkov, Maksym; Ramachandran, Arthi; Chaintreau, Augustin; Legout, Arnaud (2016). "Social clicks: What and who gets read on Twitter?". Procs of the 2016 ACM Sigmetrics intl conf on measurement and modeling of computer science. https://hal.inria.fr/hal-01281190

Galdón, Gabriel (2001). Desinformación. Método, Aspectos y soluciones. Navarra: Eunsa. ISBN: 9788431324186

Habermas, Jürgen (2003). Mudança estrutural na esfera pública: investigações quanto a uma categoria da sociedade burguesa. 2.ed. Rio de Janeiro: Tempo Brasileiro. ISBN: 1580193536047

Herring, Susan (2010). “Web content analysis: Expanding the paradigm”. In: Hunsinger, Jeremy; Klastrup, Lisbeth; Allen, Matthew M. (eds.). International handbook of internet research. New York: Springer Verlag, pp. 233-249. ISBN 9781 402097898

Krippendorf, Klaus (2004). Content analysis: An introduction to its methodology (2 ${ }^{\text {nd }}$ ed.). Thousand Oaks, CA: Sage. ISBN: 0761915443

Martínez-Albertos, José-Luis (1977). El mensaje informativo. Barcelona: ATE. ISBN: 9788485047871 
Medeiros, Jackson-da-Silva (2013). “Considerações sobre a esfera pública: redes sociais na internet e participação política”. TransInformação, v. 25, n. 1, pp. 27-33.

https://doi.org/10.1590/S0103-37862013000100003.

November, Alan (2016). Mission critical: How educators can help save democracy.

https://novemberlearning.com/assets/MissionCriticalHowEducatorsCanHelpSaveDemocracy.pdf

Recuero, Raquel (2009). Redes sociais são grupos de atores.

http://www.ihu.unisinos.br/entrevistas/23660-redes-sociais-sao-grupos-de-atores-entrevista-com-raquel-recuero

Shearer, Elisa; Gottfried, Jeffrey (2016). "News use across social media platforms." Pew Research Center, May 26. https://www.journalism.org/2016/05/26/news-use-across-social-media-platforms-2016

Shirky, Clay (2011). "The political power of social media: Technology, the public sphere, and political change”. Foreign affairs, v. 90, n. 1, pp. 28-41.

https://www.jstor.org/stable/25800379

Silverman, Craig; Singer-Vine, Jeremy (2016). "Most Americans who see fake news believe it, new survey says". BuzzFeed news, December 6.

https://github.com/BuzzFeedNews/2016-12-fake-news-survey

Tandoc Jr., Edson C.; Lim, Zeng-Wei; Ling, Richard (2017). “Defining 'fake news'”. Digital journalism, v. 6, n. 2, pp. $137-153$. https://doi.org/10.1080/21670811.2017.1360143

Thorson, Emily (2008). "Changing patterns of news consumption and participation". Information, communication \& society, v. 11, n. 4, pp. 473-489.

https://doi.org/10.1080/13691180801999027

Törnberg, Petter (2018). "Echo chambers and viral misinformation: Modeling fake news as complex contagion". PLoS one, v. 13, n. 9, pp. 1-21.

https://doi.org/10.1371/journal.pone.0203958

Volkoff, Vladimir (2000). Pequena história da desinformação: do cavalo de Tróia à Internet. Lisboa: Editorial Notícias. ISBN: 9724611558

Wardle, Claire (2017). "Fake news. It's complicated". Medium.com, February 16. https://medium.com/1st-draft/fake-newsits-complicated-d0f773766c79

Wardle, Claire; Derakhshan, Hossein (2018). "Thinking about 'information disorder': formats of misinformation, disinformation, and mal-information". In: Ireton, Cherilyn; Posetti, Julie. Journalism, 'fake news' \& disinformation. Paris: Unesco, pp. 43-54. ISBN: 9789231002816

\section{El profesional de la información Servicio de traducciones al inglés}

http://www.elprofesionaldelainformacion.com/documentos/traducciones.pdf

Información: Isabel Olea epi.iolealagmail.com 